\title{
Erratum to: Comparative reliability analysis of ships under vector-load processes
}

\author{
Huirong Jia • Torgeir Moan
}

Published online: 21 July 2010

(C) JASNAOE 2010

Erratum to: J Mar Sci Technol (2009) 14:485-498

DOI 10.1007/s00773-009-0061-6

This paper was published as a Review Article, but it should have been categorized as an Original Article.

The online version of the original article can be found under doi:10.1007/s00773-009-0061-6.

H. Jia ( $\square)$

Centre for Ships and Ocean Structures,

Norwegian University of Science and Technology,

Otto Nielsens v 10, 7491 Trondheim, Norway

e-mail: huirong.jia@ntnu.no

\section{T. Moan}

Department of Marine Technology/Centre for Ships and Ocean Structures, Norwegian University of Science and Technology,

Otto Nielsens v 10, 7491 Trondheim, Norway 